\title{
Síndrome de Munchausen: relato de caso e revisão da literatura
}

\section{Munchausen's Syndrome: a case report and literature review}

\author{
Ana Paula T de Menezes, Érica de M Holanda, Virgínia Angélica L Silveira, Kelma Cristina da S de Oliveira e Francisco George M \\ Oliveira
}

Hospital Universitário Walter Cantídio (HUWC) da Universidade Federal do Ceará (UFC). Fortaleza, CE, Brasil

Resumo Descrita pela primeira vez pelo médico inglês Richard Asher, em 1951, a síndrome de Munchausen (SM) é um transtorno factício em que o paciente se mostra aguda e dramaticamente doente, com a habilidade de mimetizar sinais e sintomas de forma a necessitar de internações prolongadas, procedimentos de diagnósticos invasivos, longo tempo de terapia com as mais variadas classes de drogas e cirurgias. Descreve-se um caso de SM do Hospital Universitário Walter Cantídio, da Universidade Federal do Ceará, em que a paciente apresentava artrite e enfisema subcutâneo. Na ocasião, ela tinha 26 anos, era agente de saúde e tinha sérios problemas familiares. Este estudo também aborda uma revisão de literatura.

Descritores Síndrome de Munchausen. Doença artificial. Enfisema subcutâneo.

Abstract First described in 1951 by Richard Asher, the Munchausen's Syndrome (MS) is a factitious disorder where the patient is acutely and severely ill and he/she is able to mimic sings and symptoms s resulting in long hospitalizations, invasive diagnostic procedures and prolonged therapies with a variety of drugs and surgeries. The case of a 26year-old woman with arthritis and subcutaneous enphysema hospitalized at the university hospital in the state of Ceará is described. At that time, the patient was a health professional and had serious family problems. A literature review is also carried out.

Keywords Munchausen syndrome. Artificial disease. Subcutaneous emphysema.

\section{Introdução}

Descrita pela primeira vez pelo médico inglês Richard Asher em 1951, a síndrome de Munchausen (SM) é um transtorno factício em que o paciente se mostra aguda e dramaticamente doente, com a habilidade de mimetizar sinais e sintomas de forma a necessitar de internações prolongadas, procedimentos de diagnósticos invasivos, longo tempo de terapia com as mais variadas classes de drogas e cirurgias. ${ }^{1}$ Segundo a Associação Psiquiátrica Americana, o critério para o diagnóstico de desordem factícia é produção intencional de sinais e sintomas físicos ou psicológicos, sem que o paciente obtenha algo em troca, como ganho financeiro ou liberação de responsabilidade legal, melhora do bem-estar físico ou uso de determinadas medicações. ${ }^{2} \mathrm{Na}$ simulação, observa-se que o paciente tem objetivo de receber, com sua sintomatologia, ganho financeiro, previdenciário, judicial, pessoal e outros.

\section{Apresentação do caso}

\section{Identificação}

Paciente do sexo feminino com 26 anos, solteira, parda e católica que trabalha como agente de saúde.

\section{História da doença atual}

Cinco dias anteriores à admissão, a paciente passou a apresentar artralgia em cotovelos, punhos, interfalangeanas, joelhos e tornozelos e, um dia antes, notou aparecimento de artrite nessas articulações. Além disso, apresentou febre alta $\left(40^{\circ} \mathrm{C}\right)$. Não relatou uso de medicações para tratar as artralgias.

\section{Antecedentes}

Referiu ter tido, quando criança, febre reumática e não ter feito qualquer tipo de tratamento. Disse ser hipertensa e sentir 
uma dor precordial com queimação esporádica relacionada a esforço físico, com duração de cerca de dez minutos e sem irradiação e sintomas associados. Estava usando hidroclorotiazida e propranolol e era acompanhada regularmente no serviço de cardiologia desse hospital. Relatou um internamento por pielonefrite em 1998. A paciente foi adotada, tendo sua mãe falecido havia cerca de dois anos. Desde então, assumiu todas tarefas domésticas, a responsabilidade pelos irmãos, tornando os atritos com o pai etilista bastante freqüentes. Após esses episódios, passou a apresentar labilidade emocional e tristeza intensa. Procurou então um psiquiatra que diagnosticou depressão e indicou o uso de amitriptilina. A paciente fez uso da medicação por curto período, abandonando o tratamento em poucos meses.

\section{Exame da paciente}

Encontrava-se com estado geral bom, normotensa, pulso com 80 batimentos por minuto, presença de edema em tornozelo, calor, rubor e edema no joelho esquerdo com enfisema subcutâneo. Notou-se também ausência de focos dentários de infecção.

Sempre quando falava da mãe ou da própria vida, apresentava crises de choro.

\section{Exames complementares}

Mostraram-se negativas hemoculturas e urinoculturas para germes piogênicos e anaeróbios. Na admissão, tinha velocidade de hemossedimentação de $8 \mathrm{~mm}$, hemograma com 10.540 leucócitos $/ \mathrm{mm} 3$, sem desvio à esquerda, fator reumatóide e fator antinúcleo (FAN) negativos, transaminases, bioquímica, funções tiroidiana e renal normais. O eletrocardiograma era normal, e o teste ergométrico, negativo.

Apresentou enfisema subcutâneo ao raio-X em tornozelos e joelhos (Figura 1), cotovelo e punho esquerdos, sendo confirmado pela ultra-sonografia, que mostrava também ausência de derrame articular. Ecocardiograma, ultra-som abdominal e pélvico, colonoscopia e cintilografia óssea estavam normais. Endoscopia digestiva alta com discreto processo inflamatório no 1/3 médio do esôfago com exsudato superficial em pseudomembrana. Além disso, a biópsia revelou esofagite discreta.
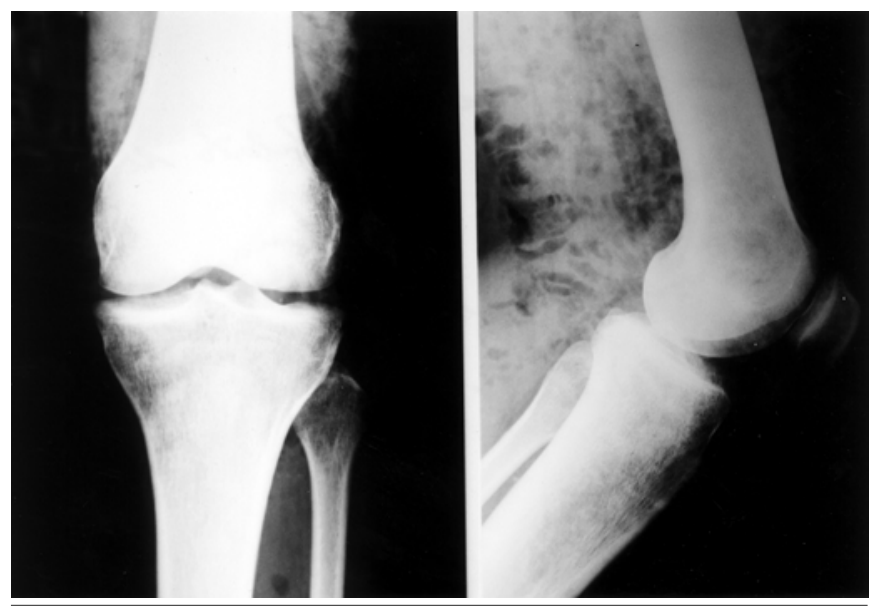

Figura 1 - Raio-X de joelho esquerdo em AP e perfil com imagem sugestiva de enfisema subcutâneo.

\section{Tratamento}

Pela possibilidade de infecção por anaeróbios ou outras bactérias produtoras de gás, foi iniciado tratamento com ceftriaxona por 21 dias e com penicilina cristalina, metronidazol e ceftazidima por 29 dias. Concomitantemente à antibioticoterapia, foram prescritos diclofenaco, indometacina e bloqueador $\mathrm{H} 2$ (ranitidina), sendo esses comprimidos encontrados no $30^{\circ}$ dia de internação junto a objetos pessoais da paciente.

\section{Evolução}

Apesar de a principal hipótese diagnóstica ser infecção anaeróbia, a paciente em nenhum momento apresentou torpor, toxemia ou qualquer outro sinal de infecção sistêmica. Durante o internamento, não se evidenciou pico febril ou hipertensivo, sendo então retiradas as medicações anti-hipertensivas. O quadro de artrite e enfisema subcutâneo era migratório, principalmente de grandes articulações e partes moles, com predomínio do lado esquerdo, em que algumas vezes se flagrava o local da punção para a injeção do ar (Figura 2). Iniciou-se, então, psicoterapia. A seguir, a paciente recebeu alta, apresentando melhora do quadro articular e não referindo novo episódio.

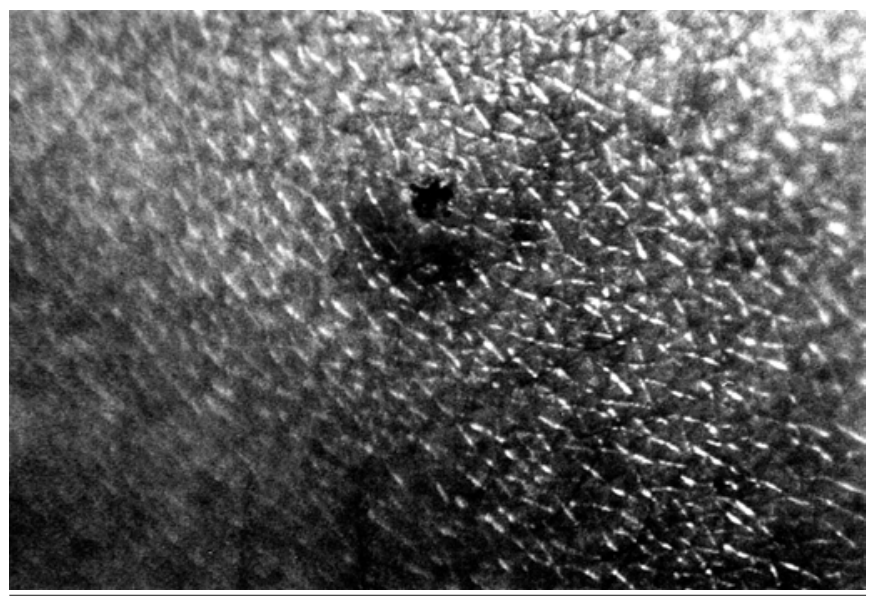

Figura 2 - Foto com lente macro do joelho esquerdo da paciente. Evidencia-se pápula eritematosa com região de ulceração na periferia, correspondendo ao local de punção com a agulha.

\section{Discussão}

A síndrome de Munchausen faz alusão a Karl Friedrich Hieronymus von Munchausen (1720-1797), barão alemão que lutou a serviço da Rússia contra os turcos no período de 1763 a 1772. Após a guerra, o barão costumava contar histórias fantásticas e fantasiosas sobre a guerra e seus atos heróicos. Em 1785, Raspe reuniu todos os contos do barão e os publicou. ${ }^{3,4}$

Existem algumas teorias sobre a patogênese da SM, como a de Pankratz \& Lezak, que descreve uma disfunção no hemisfério direito em pacientes com Munchausen; de King \& Ford, que relata anormalidades no sistema nervoso central em $40 \%$ dos 72 pacientes estudados (focos epileptogênicos, lesões cranianas de diversas etiologias, infecções prévias, anormalidades no EEG); e de Evans et al, que fala de alteração no sistema hipotalâmico-pituitário-adrenal..$^{5-9}$ História de trauma psicológico pode existir, como privações na infância, abuso infantil, 
rejeição dos pais ou de outros familiares, abandono em instituições e presença de fatores ambientais estressantes. ${ }^{4,9}$

A idade de início da SM varia de 4 a 79 anos, com uma ligeira predominância em homens (2:1). Normalmente existe alguma experiência ou contato com a área de saúde e traços de personalidade anti-social. ${ }^{8,9,10} \mathrm{O}$ paciente tem passagens por vários hospitais, sendo na maioria deles novamente investigado. Também é descrito que essas passagens por instituições podem ser apenas mais um componente fantasioso da doença. A apresentação de forma incomum ou dramática da doença é encontrada em alguns casos, e muitas vezes encontra-se evidência física da auto-indução dos sinais. ${ }^{4,9}$

Três formas clássicas da SM são descritas: laparotomaphilia migrans (dor abdominal aguda), hemorrhagia histrionica (tipo hemorrágico) e neurológica diabólica (convulsões, parestesias e outros quadros neurológicos). ${ }^{4,11}$ Além disso, são encontrados: lesões de pele, febre de origem obscura, enfisema subcutâneo, dores em geral, distúrbios endócrinos, arritmias, insuficiência respiratória, infecções de repetição, simulação de alguma patologia já descrita. ${ }^{4,10}$ Os sintomas reumatológicos são relativamente incomuns e incluem artrite séptica, osteomielite e simulação de lupus eritematoso sistêmico, artrite reumatóide e outras doenças. ${ }^{3}$ É uma patologia que demanda quase sempre altos custos, pois são necessários diversos exames, terapias e procedimentos invasivos para descartar todas as outras possibilidades diagnósticas se o paciente não for flagrado provocando sinais e sintomas característicos. O paciente também fica sujeito à morbidade e à mortalidade provocadas ou desencadeadas pela investigação e pelo tratamento. ${ }^{10}$

A forma conhecida como Munchausen por procuração é ca-

\section{Referências}

1. Asher R. Munchausen's Syndrome. Lancet 1951,1:339-41.

2. American Psychiatric Association. Diagnostic and statistical manual of mental disorders IV. Washington (DC): American Psychiatric Association; 1994.

3. Tlacuilo-Parra JA, Guevara-Gutierrez E, Garcia-De La Torre. Factitious disorders mimicking systemic lupus erytematous.Clin Exp Rheumatol 2000;18(1):89-93.

4. Case records of the Massachusetts General Hospital. Weekly clinicopathological exercises. Case 28-1984. A 39-year-old man with gas in the soft tissues of the left forearm.. New Eng1 J Med 1984;311(2):108-15.

5. Pankaratz L, Lezak MD. Cerebral Dysfunction in the Munchausen Syndrome. Hillside J Clin Psychiatry 1987;9:195-206.

6. King BH, Ford CV. Pseudologia fantastica. Acta Psychiatr Scand 1988;77:1-6.

7. Evans DL, Hsiao JK, Nemeroff CB. Munchausen syndrome, depression and the dexamethasone suppression test. Am J Psychiatry 1984;141:570-2.

8. Babe KS, Peterson AM, Loosen PT, Geracioti TD. The pathogenesis of munchausen syndrome: a review and case report. Gen Hosp Psychiatry 1992;14(4)273-6. racterizada pelo abuso infantil, de idosos e de deficientes mentais e físicos. As idades já descritas em crianças estão entre 7 semanas e 14 anos. ${ }^{9}$ Normalmente, o provocador é uma mãe jovem, com menos de 20 anos, casada e com algum transtorno de personalidade e/ou disfunção familiar. Outras pessoas envolvidas diretamente com a criança ou idoso também podem ser autoras dos sintomas., ${ }^{4,9}$

$\mathrm{O}$ tratamento da doença se baseia principalmente em psicoterapia individual ou de grupo e em medidas de suporte físico, psicológico e social. Tentam-se buscar motivos para o transtorno, conscientização do paciente que aquilo pode ser prejudicial a ele, conforto para tentar chegar à resolução dos problemas psicológicos e evitar recidivas. O uso de medicações, como antidepressivos, pode ser necessário. ${ }^{4} \mathrm{O}$ confronto com o paciente em relação a suas ações e doença não deve ser feito em todos os casos, deve ser realizado por pessoa bem treinada nesse tipo de abordagem, pois pode levar o paciente à negação com conseqüente evasão do hospital ou tratamento., ${ }^{4,9}$

A paciente descrita acima injetava ar com uma seringa descartável em diversas regiões do corpo, levando a quadros de artrite e enfisema subcutâneo. Foi submetida à longa terapia com antibióticos e diversos exames diagnósticos. A confirmação da síndrome veio com a localização de locais de punção no joelho e mão esquerda, das medicações prescritas durante um mês no hospital nos seus objetos pessoais e das seringas descartáveis em locais pouco comuns. Dessa maneira, destacase a hipótese de que a morte da mãe (figura protetora), o convívio com o pai agressivo, a responsabilidade com as tarefas domésticas e com os irmãos possam ter motivado a paciente a produzir o transtorno factício, levando ao diagnóstico de SM.

9. Folks DG. Munchausen's syndrome and other factitious disorders. Neurol Clin 1995;13(2):267-81.

10. Altman JS, Gardner GM. Cervicofacial subcutaneous emphysema in a patient with munchausen syndrome. Ear Nose Throat J 1998;77(6):476-82.

11. Ludviksson BR, Griffin J, Graziano FM. Munchausen's syndrome: the importance of a comprehensive medical history. Wis Med J $1993 ; 92(3): 128-9$.

\section{Correspondência:}

Ana Paula Teixeira de Menezes

Rua Pereira Filgueiras, 1.405, Aldeota

60160-150 Fortaleza,CE, Brasil

Tel.: (0xx85) 226-6549

E-mail: emholanda@hotmail.com (Erica Holanda) 